the expression levels of soluble protein between the Vertiga screening trials and large-scale growth conditions (Table 1). In contrast, without the Vertiga shaker, the correlation between microliter- and milliliter- (and liter) scale expression is much lower (data not shown). The two proteins that behaved differently between micro- and macro-expression, BH0832 (GenBank ${ }^{\circledR}$ accession no. 10173447) and AGR_L_2357p (accession no. 15159665), did so in only one of the two experiments; in the second, the micro- and macro-expression behavior was identical for both proteins (Table 1). Finally, eukaryotic proteins from Saccharomyces cerevisiae and viral proteins from the Severe Acute Respiratory Syndrome (SARS) virus have also been successfully micro-expressed in E. coli using this device.

These results demonstrate that the microliter-scale expression protocol developed using the Vertiga vertical shaker can be used to accurately identify proteins that will express solubly in larger-scale fermentation conditions. Moreover, the results from these screens can be used to assess the solubility and expected protein yield for each potential protein target for both native and labeled $E$. coli recombinant expression. Future developments include using material directly from microliter-scale expression for biophysical analysis, including nanovolume crystallization (10) and other biophysical techniques currently being miniaturized.

\section{ACKNOWLEDGMENTS}

This work was supported in part by grant no. GM62411 (to I.A. Wilson, P.I., JCSG) from the National Institutes of Health (NIH) Protein Structure Initiative. We appreciate the assistance of Lee Clark, Jim Jasco from Glas-Col, Mark Knuth and Ciaran Cronin from Syrrx for the initial studies of the Vertiga system, and Scott Lesley, Mark Weselak, and Bob Downs for the GNF fermenter design.

\section{COMPETING INTERESTS STATEMENT}

The authors declare that they have no competing interests.

\section{REFERENCES}

1.Holz, C., O. Hesse, N. Bolotina, U. Stahl, and C. Lang. 2002. A micro-scale process for highthroughput expression of cDNAs in the yeast Saccharomyces cerevisiae. Protein Expr. Purif. 25:372-378

2.Shih, Y.-P., W.-M. Kung, J.-C. Chen, C.-H. Yeh, A.H.-J. Wang, and T.-F. Wang. 2002. High-throughput screening of soluble recombinant proteins. Protein Sci. 11:1714-1719.

3.Adams, M.W.W., H.A. Dailey, L.J. DeLucas, M. Luo, J.H. Prestegard, J.P. Rose, and B.C. Wang. 2003. The Southeast Collaboratory for Structural Genomics: a high-throughput gene to structure factory. Acc. Chem. Res. 36:191-198.

4.Nguyen, H., B. Martinez, N. Oganesyan, and K. Rosalind. 2004. An automated small-scale protein expression and purification screening provides beneficial information for protein production. J. Struct. Funct. Genomics 5:23-27.

5.Scheich, C., V. Sievert, and K. Büssow. 2003. An automated method for high-throughput protein purification applied to a comparison of His-tag and GST-tag affinity chromatography. BMC Biotechnol. 3:12-19.

6.Knaust, R.K.C. and P. Nordlund. 2001. Screening for soluble expression of recombinant proteins in a 96-well format. Anal. Biochem. 297:79-85.
7.Yokoyama, S. 2003. Protein expression systems for structural genomics and proteomics. Curr. Opin. Chem. Biol. 7:39-43.

8.Hendrickson, W.A., J.R. Horton, and D.M. LeMaster. 1990. Selenomethionyl proteins produced for analysis by multiwavelength anomalous diffraction (MAD): a vehicle for direct determination of three-dimensional structure. EMBO J. 9:1665-1672.

9.Lesley, S.A., P. Kuhn, A. Godzik, A.M. Deacon, I. Mathews, A. Kreusch, G. Spraggon, H.E. Klock, et al. 2002. Structural genomics of the Thermotoga maritima proteome implemented in a high-throughput structure determination pipeline. Proc. Natl. Acad. Sci. USA 99:11664-11669.

10.Santarsiero, B.D., D.T. Yegian, C.C. Lee, G. Spraggon, J. Gu, D. Scheibe, D.C. Uber, E.W. Cornell, et al. 2002. An approach to rapid protein crystallization using nanodroplets. J. Appl. Crystallogr. 35:278-281.

Received 19 April 2004; accepted 1 June 2004.

Address correspondence to Raymond C. Stevens, The Scripps Research Institute, 10550 North Torrey Pines Road, La Jolla, CA 92037,USA.e-mail: stevens@scripps.edu

\title{
Robust expression of transgenes in MCF-7 breast cancer cells is expression vector-dependent
}

\author{
Paul Winnard, Jr., Yelena Mironchik, and Venu Raman \\ The Johns Hopkins University, Baltimore, MD, USA
}

BioTechniques 37:370-374 (September 2004)

We are reporting that the in vivo protein expression in mammalian MCF-7 breast cancer cells can be highly dependent on the type of commercially available expression vectors used. Figure 1 is a representation of the vector backbones used and indicates the position of our genes of interest (denoted Insert) relative to the cytomegalovirus (CMV) promoter and simian virus 40 (SV40) poly(A) signal sequence in a pCMVTag4A vector (Stratagene, La Jolla, CA, USA), which resulted in an in-frame fusion at the 3' end with a $\mathrm{FLAG}^{\circledR}$ epitope sequence. Figure 1 also depicts the placement of these FLAG-tagged genes (including a TGA stop codon) into a pEF- $1 \alpha$ His/Myc vector (Invitrogen, Carlsbad, CA, USA) and their relative positions with respect to the elongation factor- $1 \alpha$ $(\mathrm{EF}-1 \alpha)$ promoter and bovine growth hormone (BGH) poly(A). Thus, except for the vector backbones, both fusion gene construct sequences were identical in the two vector systems. Sequencing analyses proved that each gene sequence was correct and in-frame with the FLAG sequence and stop codon. All plasmids were prepared using the Qiagen ${ }^{\circledR}$ Plasmid Midi Kits (Qiagen, Valencia, CA, USA). Initial transient 
transfection experiments indicated that little or no transgene-encoded proteins were made in MCF-7 cells transfected with the Stratagene vector constructs. In order to eliminate the possibility that the Stratagene-based plasmid preparations were contaminated with an inhibitory substance(s) or had some mutations, we performed a second round of experiments. Stratagene-based plasmid constructs were grown, put through two rounds of plasmid purification (260:280 $=1.75$ to 1.80 ), and once again sequenced, which eliminated the questions about any acquired mutations. In order to semiquantitatively evaluate transgene expression, transient transfection experiments included either the Renilla luciferase or enhanced green fluorescent protein (EGFP) reporter expression vectors. Figure 2 shows a representative immunoblot (out of three that were semiquantitative blots and seven nonquantified blots). Figure 2 indicates that $\mathrm{EF}-1 \alpha-\mathrm{BGH} \mathrm{p}(\mathrm{A})$ vector constructs provide a sequence context, which in MCF-7 cells, drives considerably higher transgene expression (lanes 1 and 3 ) than the CMVSV40 $\mathrm{p}(\mathrm{A})$ vector constructs (lanes 2 and 4) within our experimental conditions. Protein bands seen in lanes 2 and 4 of Figure 2 only become visible after prolonged exposure (30 $\mathrm{min})$, which is an indication of the low expression of the FLAG-tagged proteins in cells transfected with the Stratagene CMV promoter-SV40 p(A)-based vector constructs. In contrast, $10 \mathrm{~s}$ exposures (data not shown) were more than adequate for the visualization of proteins driven of the EF- $1 \alpha$-based vectors. These results indicate that in MCF-7 breast cancer cells, transgene expression can be highly dependent upon the expression vector used. However, in order to obtain a better understanding of the vector component(s) that may be primarily responsible for the enhanced expression seen with the EF-1 $\alpha$-based vectors, we replaced the EF- $1 \alpha$ promoter in one of our EF- $1 \alpha$ vectors with the CMV promoter from pCMVTag4A-Flag for use in another round of transient transfection experiments. Figure 3 illustrates that the CMV promoter can generate protein expression levels that are only about two times less than those generated by the EF- $1 \alpha$ promoter when it is within the context of the EF-1 $\alpha$-based

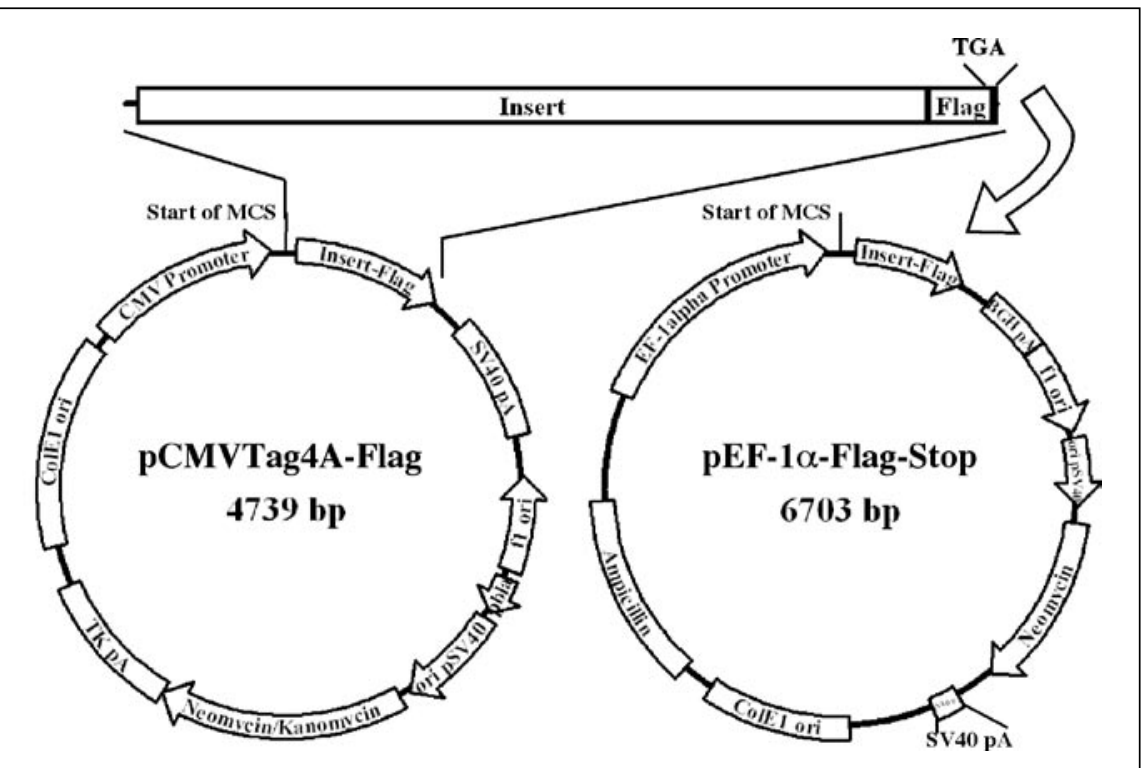

Figure 1. Illustration of the mammalian expression vector constructs used in this study. Locations of each vector's major regulatory components along with the genes of choice (labeled Insert) are depicted. Differences include promoters and polyadenylation signal sequences as well as the placement of the ColE1 ori sequences and vector size. Genes were inserted into Stratagene's pCMVTag4A vector in-frame with a FLAG epitope sequence. FLAG-tagged genes along with TGA stop codons were excised from the pCMVTag4A-Flag vectors with SacII and KpnI digestion, blunt-ended (T4 DNA polymerase), and ligated into the EcoRV site of Invitrogen's pEF-1 $\alpha$-His/Myc vector, creating the pEF-1 $\alpha$-Flag-stop constructs. MCS, multiple cloning site; CMV, cytomegalovirus; TK, thymidine kinase; EF-1 $\alpha$, elongation factor- $1 \alpha$; SV40, simian virus 40; pA, polyadenylation; BGH, bovine growth hormone.

vector backbone. Taken together, these results indicate that vector-driven in vivo protein expression in $\mathrm{MCF}-7$ cells can be vector-dependent. The cases tested here, Invitrogen's pEF$1 \alpha$-His/Myc vector versus Stratagene's pCMVTag4A vector, show that the majority of the loss of protein expression

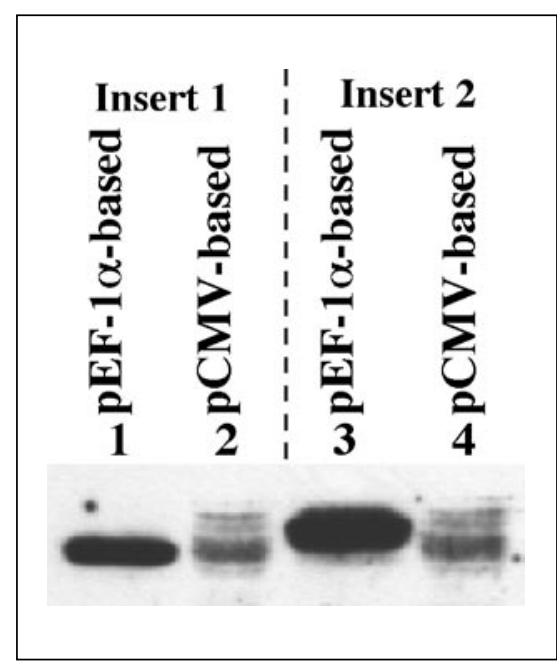

Figure 2. Representative immunoblot indicating protein expression levels in cell lysates from transiently transfected MCF-7 cells. Lanes 1 and 3 indicate the large amounts of protein expression obtained from $\mathrm{pEF}-1 \alpha$-His/Myc vector constructs as compared to the low levels of protein expression (lanes 2 and 4 ) obtained from the pCMVTag4A vector construct. Two different FLAG-tagged proteins are shown: lanes 1 and 2 (Insert 1) versus lanes 3 and 4 (Insert 2).

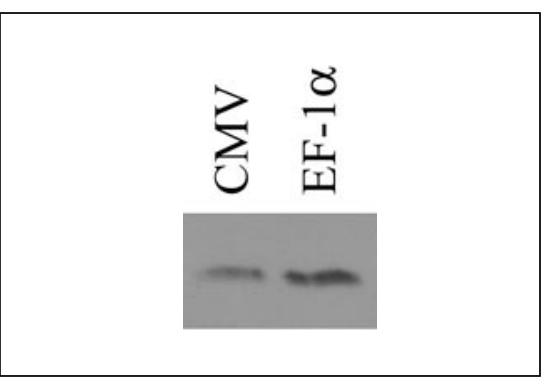

Figure 3. Representative immunoblot comparing protein expression levels from $\mathrm{pEF}-1 \alpha$ His/Myc vector constructs in cell lysates from transiently transfected MCF-7 cells. The righthand lane shows protein expression from one of our $\mathrm{pEF}-1 \alpha$-Flag-Stop vector constructs. The lefthand lane shows protein expression from a vector prepared from the same $\mathrm{pEF}-1 \alpha$-Flag-Stop vector construct where the elongation factor- $1 \alpha(\mathrm{EF}-1 \alpha)$ promoter has been replaced by the cytomegalovirus (CMV) promoter. This blot indicates that, even within the context of an identical vector backbone, the EF- $1 \alpha$ promoter gives higher protein expression (approximately 2 -fold higher; $n=2$ ) than the CMV promoter. Protein loading was normalized to Renilla luciferase luminescence. 
from pCMVTag4A-based constructs can be attributed to vector components or an arrangement of vector components in Stratagene's vector backbone other than its promoter. However, under the conditions used within this study, the EF- $1 \alpha$ promoter consistently produced higher levels of protein.

A variety of reasons could explain these results although most have not been systematically studied by us. Mammalian expression vector development $(1,2)$ has gone hand in hand with a continuous effort to increase the efficacy of these vectors (3-6). Optimal promoter activity has often been the focus of such design efforts (e.g., Reference 5). Throughout continued testing, the CMV promoter has been proven to give robust in vivo expression of an investigator's choice of transgenes $(7,8)$. However, certain limitations with the use of the CMV promoter have also been reported. For example, it has been shown that the CMV promoter can be silenced (9). In addition, the CMV promoter can be down-regulated by wild-type p53 tumor suppressor protein (10). An alternative promoter that has come into routine use is the EF- $1 \alpha$ promoter (11-13). However, comparisons of the capabilities of the $\mathrm{CMV}$ versus the $\mathrm{EF}-1 \alpha$ promoter to drive expression of mammalian transgenes have produced equivocal results (e.g., compare Reference 8 and Reference 13). For example, Kim et al. (14) have recently reported that generally the EF- $1 \alpha$ promoter is superior in driving transgene expression as compared to the CMV promoter due to the inclusion of the first intron of the EF- $1 \alpha$ gene within the context of the promoter. Evidence is also building that the EF- $1 \alpha$ promoter may have advantages over the CMV promoter with respect to persistent transgene expression in stable clones $(11,13)$. Another component of vector engineering that has come under study has been the choice of poly(A) signal sequence $(15,16)$. Yet, as with promoter comparisons, comparisons of the SV40 poly(A) sequence versus the $\mathrm{BGH}$ poly(A) sequence can produce equivocal results $(15,16)$. These reports and others (e.g., Reference 17) indicate that many factors can contribute to the regulation of transgene expression in mammalian cells. Thus, it is prudent to analyze more than one promoter and backbone se- quence for its ability to modulate high protein expression within a given cell type or tissue. This is important if an efficient evaluation of the overexpressed protein's in vivo function(s) as well as its impact on cellular physiology is to be made. On the other hand, vector-driven synthesis of suboptimal or nondetectable quantities of protein makes an evaluation of the protein's effect(s) on cellular function a dubious and expensive task. Such considerations may be particularly pertinent in the context of cancer cells, such as MCF-7s, because dysregulation of genetic information is the norm in such cells and is likely to affect protein synthesis.

\section{ACKNOWLEDGMENTS}

This work was supported by National Institutes of Health grant no. P50 CA103175 to V.R.

\section{COMPETING INTERESTS STATEMENT}

The authors declare that they have no competing interests

\section{REFERENCES}

1.Mulligan, R.B., B. Howard, and P. Berg. 1979. Synthesis of rabbit $\beta$-globin in cultured monkey cells following infection with a SV40 $\beta$-globin recombinant genome. Nature 227:108-114.

2.Gorman, C.M., L.F. Moffat, and B.H Howard. 1982. Recombinant genomes which express chloramphicol acetyltransferase in mammalian cells. Mol. Cell. Biol. 2:10441051.

3.Takebe, Y., M. Seiki, J.-I. Fujisawa, P. Hoy, K. Yokota, K.-I. Arai, M. Yoshida, and N. Arai. 1988. SR $\alpha$ promoter: an efficient and versatile mammalian cDNA expression system composed of the simian virus 40 early promoter and the RU5 segment of human Tcell leukemia virus type 1 long terminal repeat. Mol. Cell. Biol. 8:466-472.

4.Ray, J. and F.H. Gage. 1992. Gene transfer into established and primary fibroblast cell lines: comparison of transfection methods and promoters. BioTechniques 12:598-603.

5.Wenger, R.H., H. Moreau, and P.J. Nielsen. 1994. A comparison of different promoter, enhancer, and cell type combinations in transient transfections. Anal. Biochem. 221:416-418.

6.Kaufman R.J. 2000. Overview of vector design for mammalian gene expression. Mol. Biotechnol. 16:151-160.

7.Foecking, M.K. and H. Hofstetter. 1986.
Powerful and versatile enhancer-promoter unit for mammalian expression vectors. Gene 45:101-105.

8.Lipshutz, G.S., D. Titre, M. Brindle, A.R. Bisconte, C.H. Contag, and K.M.L. Gaensler. 2003. Comparison of gene expression after intraperitoneal delivery of AAV2 or AAV5 in utero. Mol. Ther. 8:90-98.

9.Loser, P., G.S. Jennings, M. Strauss, and V. Sandig. 1998. Reactivation of the previously silenced cytomegalovirus major immediateearly promoter in the mouse liver: involvement of NFKB. J. Virol. 72:180-190.

10.Allamane, S., D. Ratel, P. Jourdes, F. Berger, A.L. Benabid, and D. Wion. 2001. p53 status and gene transfer experiments using CMV enhancer/promoter. Biochem. Biophys. Res. Commun. 280:45-47.

11.Najjar, S.M. and R.E. Lewis. 1999. Persistent expression of foreign genes in cultured hepatocytes: expression vectors. Gene 230:41-45.

12.Kim, D.W., T. Uetsuki, Y. Kaziro, N. Yamaguchi, and S. Sugano. 1990. Use of the human elongation factor 1 alpha promoter as a versatile and efficient expression system. Gene 91:217-223.

13.Chung, S., T. Andersson, K.-C. Sonntag, L. Bjorklund, O. Isacson, and K.-S. Kim. 2002. Analysis of different promoter systems for efficient transgene expression in mouse embryonic stem cell lines. Stem Cells 20:139145.

14.Kim, S.-Y., J.-H. Lee, H.-S. Shin, H.-J. Kang, and Y.-S. Kim. 2002. The human elongation factor 1 alpha $(E F-1 \alpha)$ first intron highly enhances expression of foreign genes from the murine cytomegalovirus promoter. $\mathrm{J}$. Biotechnol. 93:183-187.

15.Xu, Z.-L., H. Mizuguchi, A. Ishii-Watabe, E. Uchida, T. Mayumi, and T. Hayakawa. 2001. Optimization of transcriptional regulatory elements for constructing plasmid vectors. Gene 272:149-156.

16.Xu, Z.-L., H. Mizuguchi, A. Ishii-Watabe, E. Uchida, T. Mayumi, and T. Hayakawa. 2002. Strength evaluation of transcriptional regulatory elements for transgene expression by adenovirus vector. J. Control Release 81:155-163.

17.Chen, Z.-Y., C.-Y. He, A. Ehrhardt, and M.A. Kay. 2003. Minicircle DNA vectors devoid of bacterial DNA result in persistent and high-level transgene expression in vivo. Mol. Ther. 8:495-500.

Received 17 February 2004; accepted 12 May 2004.

Address correspondence to Venu Raman, The Johns Hopkins University, Dept of Radiology, 340 Traylor, 720 Rutland Avenue, Baltimore, MD 21205, USA. e-mail: vraman2@jhmi.edu 